\title{
Identification and Antioxidant Abilities of Enzymatic-Transesterification (-)-Epigallocatechin-3-O-gallate Stearyl Derivatives in Non-Aqueous Systems
}

\author{
Chengyu Jiang ${ }^{1,2}$, Li Wang ${ }^{1,2}$, Xin Huang ${ }^{1,2}$, Song Zhu ${ }^{1,2}$, Chaoyang Ma ${ }^{1,2}$ and Hongxin Wang ${ }^{1,2, *}$ \\ 1 State Key Laboratory of Food Science and Technology, Jiangnan University, Wuxi 214122, China; \\ jcy87injiangnan@163.com (C.J.); 6180112151@stu.jiangnan.edu.cn (L.W.); huangxin1728@163.com (X.H.); \\ zhusong@jiangnan.edu.cn (S.Z.); machaoyang24@jiangnan.edu.cn (C.M.) \\ 2 School of Food Science and Technology, Jiangnan University, Wuxi 214122, China \\ * Correspondence: hxwang@jiangnan.edu.cn; Tel.: +86-0510-85320318
}

check for updates

Citation: Jiang, C.; Wang, L.; Huang, X.; Zhu, S.; Ma, C.; Wang, H. Identification and Antioxidant Abilities of Enzymatic-Transest erification (-)-Epigallocatechin -3-O-gallate Stearyl Derivatives in Non-Aqueous Systems. Antioxidants 2021, 10, 1282. https://doi.org/ $10.3390 /$ antiox 10081282

Academic Editors: Giovanna Mobbili and Pierluigi Stipa

Received: 21 June 2021

Accepted: 3 August 2021

Published: 13 August 2021

Publisher's Note: MDPI stays neutral with regard to jurisdictional claims in published maps and institutional affiliations.

Copyright: (c) 2021 by the authors. Licensee MDPI, Basel, Switzerland. This article is an open access article distributed under the terms and conditions of the Creative Commons Attribution (CC BY) license (https:/ / creativecommons.org/licenses/by/ $4.0 /)$.

\begin{abstract}
Vinyl stearate was added to enzymatic transesterification of (-)-Epigallocatechin-3-Ogallate (EGCG) to enhance its lipophilicity and antioxidant ability in a non-aqueous system. The lipase DF "Amano" 15 was used as the catalyst. The optimal reaction conditions were: acetonitrile as the solvent, the molar ratio of vinyl stearate: EGCG as 3:1, an enzyme amount of $4.0 \%$ (ratio of substrate mass), and a reaction temperature and time of $50{ }^{\circ} \mathrm{C}$ and $96 \mathrm{~h}$, respectively, achieving $65.2 \%$ EGCG conversion. HPLC-MS and NMR were used to determine the structure of EGCG stearyl derivative (3",5"-2-O-stearyl-EGCG). The lipophilicity of EGCG stearyl derivatives (3.49 \pm 0.34$)$ was higher (5.06 times) than that of the parent EGCG $(0.69 \pm 0.08)$. Furthermore, EGCG stearyl derivatives had excellent lipid oxidation compared with BHT, BHA, and parent EGCG. The POVs of soybean oil with EGCG stearyl derivatives $(18.17 \pm 0.92 \mathrm{mEq} / \mathrm{kg})$ were significantly reduced (by $62.5 \%)$ at $21 \mathrm{~d}$ compared with those of EGCG $(48.50 \pm 1.23 \mathrm{mEq} / \mathrm{kg})$. These results indicate that EGCG derivatives have broad antioxidant application prospects in lipophilic environments/high-fat food.
\end{abstract}

Keywords: EGCG stearyl derivatives; enzymatic transesterification; non-aqueous system; identification; antioxidant ability

\section{Introduction}

Lipid oxidation is the primary cause of flavor and nutrient loss in fat-containing foods, leading to adverse physiological reactions or food poisoning [1]. In recent years, some studies have shown that synthetic fat-soluble antioxidants, such as butylated hydroxytoluene (BHT), butylated hydroxyanisole (BHA), and tert-butylhydroquinone (TBHQ) have potential toxicity and carcinogenic effects [2-4]. Many consumers prefer natural ingredients to synthetic ones. Epigallocatechin-3-O-gallate (EGCG) is the main derivative of catechins with excellent biological activity [5]. However, EGCG has a polyhydroxy structure and hydrophilicity, limiting its application under hydrophobic conditions [6]. Nonetheless, the development of natural oil-soluble antioxidants, and the modification of the physical properties of known natural water-soluble antioxidants, have attracted a lot of attention.

Research on polyphenol modification (physical, chemical, and enzymatic) has advanced significantly in recent years. However, the particles and nanoparticles of polyphenols can easily undergo precipitation, demulsification, and delamination due to stirring, heating, and long-term storage [7]. Polyphenol derivatives obtained via chemical modification have poor selectivity and antioxidant activity [8]. The entire reaction process is affected by many factors, and generates unnecessary by-products and toxic waste [9]. Tobiason first detected enzymatic modification while analyzing molecular orbitals of catechin 3-O-acylated derivatives [10]. The process mainly occurs at the 3rd hydroxyl group of non-ester catechins and the B- and D-ring hydroxyl groups of ester catechins. 
To date, various acyl donors have been associated with the acylation of flavonoids, where fatty acids are obtained due to their highest conversion degrees and reaction rates [11,12]. Enzymatic modification of EGCG mainly occurs at the 3,5-position of the hydroxyl group of the D- and B-ring of ester EGCG. The lipophilic derivatives of EGCG have an excellent partition coefficient ( $\log P$ value). The $\log P$ value and the fat solubility gradually increase with the increasing number of hydroxyl substitutions [13]. However, the conversion yields of lipophilic derivatives of flavonoids decrease (from $62 \%$ to $27 \%$ ) with the increasing fatty acid chain length [14]. Furthermore, long-chain EGCG derivatives are more stable, have stronger hydrophobicity, and have higher bioavailability than short-chain EGCG derivatives [15]. Moreover, higher lipophilicity can enhance the penetration of modified EGCG into the lipid bilayer of the cell membrane, promoting its absorption and utilization, and thereby increasing the expression of antioxidant activity in vivo [16]. In ARPE-19 cells, the monoalkylated EGCG (C18-EGCG) enhanced the protective effect against oxidative stress via the increase in lipid moiety [17]. Compared with short-chain fatty acids, the use of long-chain fatty acids can greatly improve lipid solubility and reduce the loss of phenolic hydroxyl groups, thus maintaining antioxidant activity.

Only a few studies have reported on the enzymatic molecular modification of EGCG via long-chain fatty acids. Herein, the lipophilic esterification of EGCG catalyzed by a new catalytic lipase enzyme was conducted in a non-aqueous solvent with vinyl stearate as an acyl donor. The effects of the enzyme source yield, substrate concentration, solvent system, enzyme addition, operating temperature, and reaction time on the conversion of EGCG stearyl derivatives were evaluated. HPLC-MS and NMR were used to assess the structural characteristics of EGCG stearyl derivatives. The lipophilicity and the antioxidant properties of the EGCG stearyl derivatives were determined and also compared with those of synthetic BHT, BHA, and TBHQ.

\section{Materials and Methods}

\subsection{Materials}

The immobilized enzyme of Novozym 435 (10,000 PLU/g), RMIM (275 IUN/g), TLIM (250 IUN/g), PSIM (500 U/g), and RM (275 IUN/g) were obtained from Novo Nordisk, Denmark. The immobilized enzyme of AY "Amano" 30SD and DF "Amano" 15 were acquired from Amano Enzyme (Jiangsu) Co., Ltd., (Shanghai, China). EGCG (purity 98\%) was obtained from Gosun Biotechnologies Co., Ltd. (Hangzhou, Zhejiang, China). Vinyl stearate (purity 99\%), methanol, acetone and other analytical reagents were obtained from Sinopharm Group Chemical Reagent Co., Ltd. (Shanghai, China).

\subsection{Preparation of EGCG Derivatives via Different Reaction Parameters}

The esterification reaction was conducted following the method described by Kontogianni et al. [18]. A certain amount of vinyl stearate (different molar ratios) was mixed with EGCG $(100 \mathrm{mM})$ in $20 \mathrm{~mL}$ of organic solvents. The reaction was initiated by seven immobilized lipases, stirred and incubated at $30-55^{\circ} \mathrm{C}$ for $12-96 \mathrm{~h}$ until the end of the reaction. The enzyme was then filtrated out. EGCG stearyl derivatives were stored in a $4{ }^{\circ} \mathrm{C}$ refrigerator for further experiments.

\subsection{Determination of Conversion of EGCG Derivatives}

A high-performance liquid chromatography (HPLC) method with a Waters 2998 Diode Array Detector (DAD), an Agilent SB-C18 column $(150 \times 4.6 \mathrm{~mm}, 5 \mu \mathrm{m})$, and a Waters 600 pump was used to assess the conversion of EGCG derivatives. The mobile phase contained $0.1 \%$ trifluoroacetic acid (A) and acetonitrile (B) with a gradient curve of $5-100 \%$ (B) for $0-20 \mathrm{~min}, 100 \%$ (B) for $20-25 \mathrm{~min}, 100-5 \%$ (B) for $25-30 \mathrm{~min}$, and $5 \%$ (B) for $30-35 \mathrm{~min}$ at a flow rate of $1 \mathrm{~mL} / \mathrm{min}$. The injection volume was $5 \mu \mathrm{L}$ at $280 \mathrm{~nm}$. The conversion of EGCG was calculated as follows:

$$
\operatorname{Tr}(\%)=\left(\mathrm{A}_{1}-\mathrm{A}_{0}\right) / \mathrm{A}_{1} \times 100 \%
$$


where Tr indicates the conversion of EGCG (\%); $\mathrm{A}_{0}$ and $\mathrm{A}_{1}$ represent the content of EGCG in the sample and the standard $(\mu \mathrm{g} / \mathrm{mL})$, respectively.

\subsection{Purification and Identification of EGCG Stearyl Derivatives}

The purification was performed via the semipreparative HPLC system with a Waters 1525 pump, a H\&E SP ODS-A column, and a Waters 2998 DAD. The mobile phase contained $0.1 \%$ acetic acid (A) and methanol (B) with a linear gradient of $5-100 \%$ B for $0-30 \mathrm{~min}$ at a flow rate of $5 \mathrm{~mL} / \mathrm{min}$ and wavelength of $280 \mathrm{~nm}$. The injection volume was $1 \mathrm{~mL}$.

The MALDI SYNAPT MS system (Waters, San Jose, MA, USA) was used as follows: positive mode, $400{ }^{\circ} \mathrm{C}$ of desolvation temperature, $3.5 \mathrm{kV}$ of capillary voltage, 30 psi of nebulizer, and $5 \mathrm{~min}$ of dwell time. A nuclear magnetic resonance (NMR) spectrometer (Bruker BioSpin $\mathrm{GmbH}$, Rheinstetten, Germany) was used to assess the grafting position of hydroxy for chemical shifts analysis of EGCG derivatives to standard EGCG.

\subsection{Determination of 1-Octanol/Water Partition Coefficient}

Lipophilicity was measured as described by Chen and Yu [19]. Briefly, the deionized water and octanol were thoroughly stirred for $24 \mathrm{~h}$. The sample $(0.2 \mu \mathrm{mol})$ was dissolved in $5 \mathrm{~mL}$ of upper phase (presaturated octanol). Deionized water $(5 \mathrm{~mL})$ was then added, vortexed and allowed to stand for separation. The absorbance of the upper phase $\left(\mathrm{C}_{0}\right)$ and the bottom phase $\left(C_{\mathrm{w}}\right)$ was measured at $280 \mathrm{~nm}$. $\log P$ was calculated using the following equation:

$$
\log \mathrm{P}=\log \left(\mathrm{C}_{0} / \mathrm{C}_{\mathrm{w}}\right) .
$$

where $C_{0}$ and $C_{w}$ indicate the sample in the upper bottom phases, respectively.

\subsection{Determination of Radical Scavenging Ability of 2,2-Diphenylpicrylhydrazyl (DPPH)}

The radical scavenging activity of DPPH was determined using the method described by Gordon et al. [20], with some modifications. In brief, a mixture of $0.1 \mathrm{~mL}$ of the sample $(1 \mathrm{mg} / \mathrm{mL})$ and $3.9 \mathrm{~mL}$ of DPPH $(25 \mathrm{mg} / \mathrm{L})$ was placed in the dark for $30 \mathrm{~min}$ and measured at $517 \mathrm{~nm}$ (UV-1800PC, MAPADA, Shanghai, China). A control was also analyzed. The radical scavenging ability was calculated as follows:

$$
\text { DPPH radical scavenging activity }(\%)=\left[\left(\mathrm{A}_{C}-\mathrm{A}_{\mathrm{S}}\right) / \mathrm{A}_{\mathrm{C}}\right] \times 100 \%
$$

where $A_{S}$ indicates the value with the sample, while $A_{C}$ shows the value without a sample.

\subsection{Determination of Radical Scavenging Ability of 2,2-Azino-bis (3-Ethylbenzothiazoline-6-sulfonate) (ABTS)}

The radical scavenging activity of ABTS was measured using the method described by Asikin et al. [21]. $\mathrm{K}_{2} \mathrm{~S}_{2} \mathrm{O}_{8}(88 \mu \mathrm{L})(140 \mathrm{mM})$ and $5 \mathrm{~mL}$ of ABTS solution $(7 \mathrm{mM})$ were mixed and put in the dark for $16 \mathrm{~h}$. The samples $(1 \mathrm{mg} / \mathrm{mL})$ were diluted with ethanol to $1180 \mu \mathrm{L}$, then $20 \mu \mathrm{L}$ of ABTS solution was added. The absorbance was measured after $3 \mathrm{~min}$ at $734 \mathrm{~nm}$. A blank was also analyzed. The radical scavenging ability was calculated as follows:

$$
\text { ABTS radical scavenging ability }(\%)=\left[\left(\mathrm{A}_{C}-\mathrm{A}_{S}\right) / \mathrm{A}_{\mathrm{C}}\right] \times 100 \%
$$

where $A_{S}$ indicates the value with the sample, and $A_{C}$ shows the value without a sample.

\subsection{Reducing Power Assay}

The reducing power assay was conducted as described by Gülçin et al. [22]. In brief, a mixture of the sample $(250 \mu \mathrm{L}), \mathrm{KH}_{2} \mathrm{PO}_{4}$ buffer $(250 \mu \mathrm{L}, \mathrm{pH} 7.5)$, and potassium ferricyanide $(1 \%(w / v), 250 \mu \mathrm{L})$ was bathed at $50{ }^{\circ} \mathrm{C}$ for $20 \mathrm{~min}$. Trichloroacetic acid $(10 \%(w / v), 250 \mu \mathrm{L})$ was then added and centrifuged, and the supernatant was obtained. A mixture of the supernatant $(500 \mu \mathrm{L})$, distilled water $(500 \mu \mathrm{L})$, and ferric chloride $(0.1 \%(w / v), 100 \mu \mathrm{L})$ was placed in darkness for $15 \mathrm{~min}$. Absorbance was measured at $700 \mathrm{~nm}$. 


\subsection{Determination of Hydroxyl Antioxidant Ability}

The antioxidant ability of hydroxyl was determined using the method described by Kong et al. [23]. In brief, a mixture of the sample $(1 \mathrm{mg} / \mathrm{mL}), 1.0 \mathrm{~mL} \mathrm{FeSO}_{4}(6.0 \mathrm{mM})$, and $1.0 \mathrm{~mL} \mathrm{H}_{2} \mathrm{O}_{2}(2.5 \mu \mathrm{M})$ was incubated at $37^{\circ} \mathrm{C}$ for $10 \mathrm{~min}$. Salicylic acid $(6.0 \mathrm{mM})(1.0 \mathrm{~mL})$ was then added to initiate the reaction and bathed at $37^{\circ} \mathrm{C}$ for $30 \mathrm{~min}$. The absorbance was determined at $500 \mathrm{~nm}$. The antioxidant ability of hydroxyl was calculated as follows:

$$
\text { Hydroxyl antioxidant ability }(\%)=\left[\left(\mathrm{A}_{0}-\left(\mathrm{A}_{1}-\mathrm{A}_{2}\right) / \mathrm{A}_{0}\right] \times 100 \%\right.
$$

where $A_{0}, A_{1}$, and $A_{2}$ indicate the absorbance of the control, sample, and reagent without sodium salicylate, respectively.

\subsection{Determination of Oxygen Radical Absorbance Capacity (ORAC)}

The ORAC assay was conducted as described by Re et al. [24]. The sample $(20 \mu \mathrm{L})$ was mixed with fluorescein $(160 \mu \mathrm{L}, 1.6 \mathrm{nM})$. AAPH $(306 \mu \mathrm{M}, 20 \mu \mathrm{L})$ was then added to initiate the reaction. A fluorescence plate reader (Thermo Fisher Scientific, Waltham, MA, USA) was used to measure the fluorescence every $2 \mathrm{~min}$ for $2 \mathrm{~h}$ at $538 \mathrm{~nm}$ of emission wavelength and $485 \mathrm{~nm}$ of excitation wavelength.

\subsection{Determination of Lipid Oxidation at Storage}

The sample $(6 \mathrm{mg})$ was mixed with $30 \mathrm{~g}$ of soybean oil, vortexed, and kept at $60^{\circ} \mathrm{C}$ for $21 \mathrm{~d}$. The peroxide values (POV) were measured every $3 \mathrm{~d}$ according to the GB/T5009.2272016. In brief, a mixture of test material $(2 \mathrm{~g})$, chloroform-glacial acetic acid $(30 \mathrm{~mL})$, and saturated potassium iodide $(1 \mathrm{~mL})$ were placed in darkness for $3 \mathrm{~min}$. Water $(50 \mathrm{~mL})$ was added, then the mixture was titrated with sodium thiosulfate $(10 \mathrm{mM})$ immediately until a light yellow color appeared. A starch indicator $(1 \mathrm{~mL})$ was added, and the mixture titrated until the blue color disappeared. A blank was prepared under the same conditions. The POV was calculated as follows:

$$
\mathrm{X}=\frac{(\mathrm{V}-\mathrm{V} 0) * \mathrm{c} * 0.1269}{\mathrm{~m}} * 100 \%
$$

where $\mathrm{X}$ indicates the mequiv of active oxygen per kilogram of soybean oil; $\mathrm{V}$ and $\mathrm{V}_{0}$ show the volume of sodium thiosulfate in the sample and the blank, respectively; $c$ indicates the concentration of sodium thiosulfate; $\mathrm{m}$ shows the quality of the test material; 0.1269 is the quality of iodine equivalent to $1 \mathrm{~mL}$ of sodium thiosulfate solution; and 100 is the conversion factor.

\subsection{Statistical Analysis}

Each experiment had three replicates. The results were expressed as mean \pm standard deviation (SD). A one-way analysis of variance (ANOVA) was used to determine the significant differences between the multiple groups, with LSD and HSD methods in SPSS22.0. $p<0.05$ was considered a significant difference.

\section{Results and Discussion}

\subsection{Effect of Various Extraction Factors on the Synthesis of EGCG Derivatives}

Enzymatic modification has mild reaction conditions and specific reaction characteristics [25]. Conversions of EGCG catalyzed by seven different lipases are shown in Figure 1. Lipase DF "Amano" 15 had the highest catalytic ability of 44.7\%, indicating high activity and stability, similar to lipase-catalyzed esterification [26]. Lipase Rhizomucor miehei (RMIM) and Novozym 435 (Candida antarctica) are selective to short and medium fatty acids [27], while DF"Amano" 15 (Rhizopus oryzae) may present high activity on a long alkyl chain. 


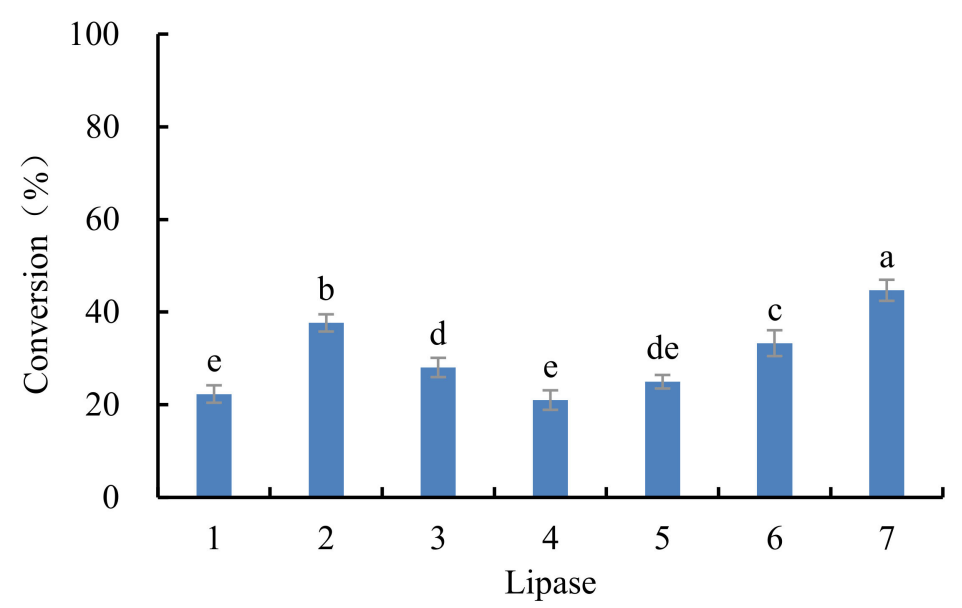

Figure 1. The conversion of EGCG by different lipases (reaction conditions: EGCG, 1 mmol; vinyl stearate, $3 \mathrm{mmol}$; enzyme, $5.0 \%$ ( $w / w$ of all substrates)); reaction temperature, $40{ }^{\circ} \mathrm{C}$; reaction time, $48 \mathrm{~h}$ in acetonitrile. 1: Novozym 435; 2: TLIM; 3: PSIM; 4: RMIM; 5: RM; 6: AY "Amano" 30SD; 7: DF "Amano" 15. Bars with different letters are significantly different at $p<0.05$.

Biocatalysts are more stable in non-polar solvents than polar solvents [28]. Hazarika, et al. [29] showed that solvents with small $\log P$ values could enhance the conversion. The conversion of EGCG (catalyzed by DF "Amano" 15) in various organic solvents is shown in Figure 2. Lipasecatalyzed esterification of EGCG in acetonitrile had the highest conversion (52.9\%).

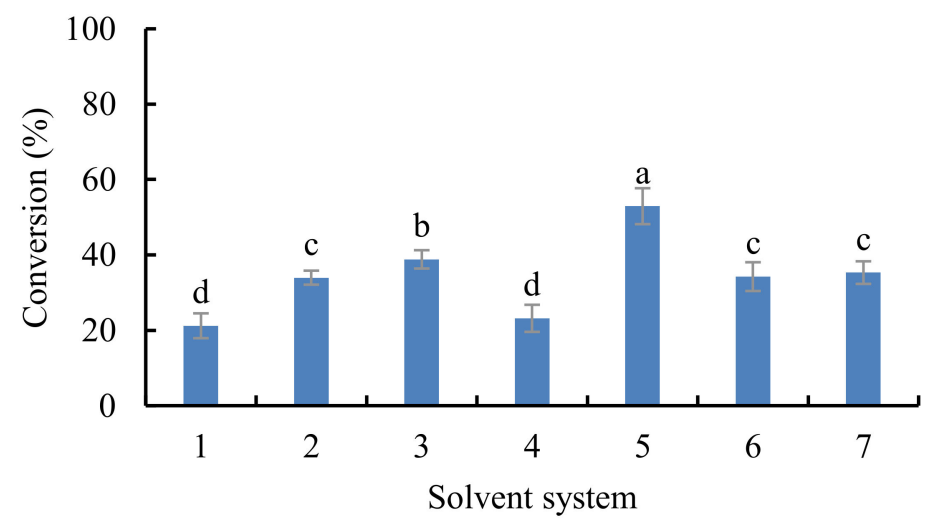

Figure 2. Conversion of EGCG by different solvent systems (reaction conditions: EGCG, 1 mmol; vinyl stearate, $3 \mathrm{mmol}$; enzyme, 5.0\% lipase DF "Amano" 15 ( $w / w$ of both substrates)); reaction temperature, $50{ }^{\circ} \mathrm{C}$; reaction time, $48 \mathrm{~h}$ in different solvent systems. 1: methanol; 2: ethanol; 3: isopropanol; 4: isopentanol; 5: acetonitrile; 6: acetone; 7: ethyl acetate. Bars with different letters are significantly different at $p<0.05$.

The effect of enzyme amount (lipase DF "Amano" 15) on the synthesis of EGCG derivatives in acetonitrile is shown in Figure 3A. The conversion increased with the increase in enzyme amount (from $2.0 \%$ to $4.0 \%$ ), but decreased with further increases in the enzyme amount (from $4.0 \%$ to $10.0 \%)(p<0.05)$. Yang et al. [30] have suggested that the enzyme particles tend to aggregate at high enzyme concentrations, which is not conducive for effective enzyme and substrate collision. These results suggest that $4.0 \%$ was the optimal concentration of lipase. 

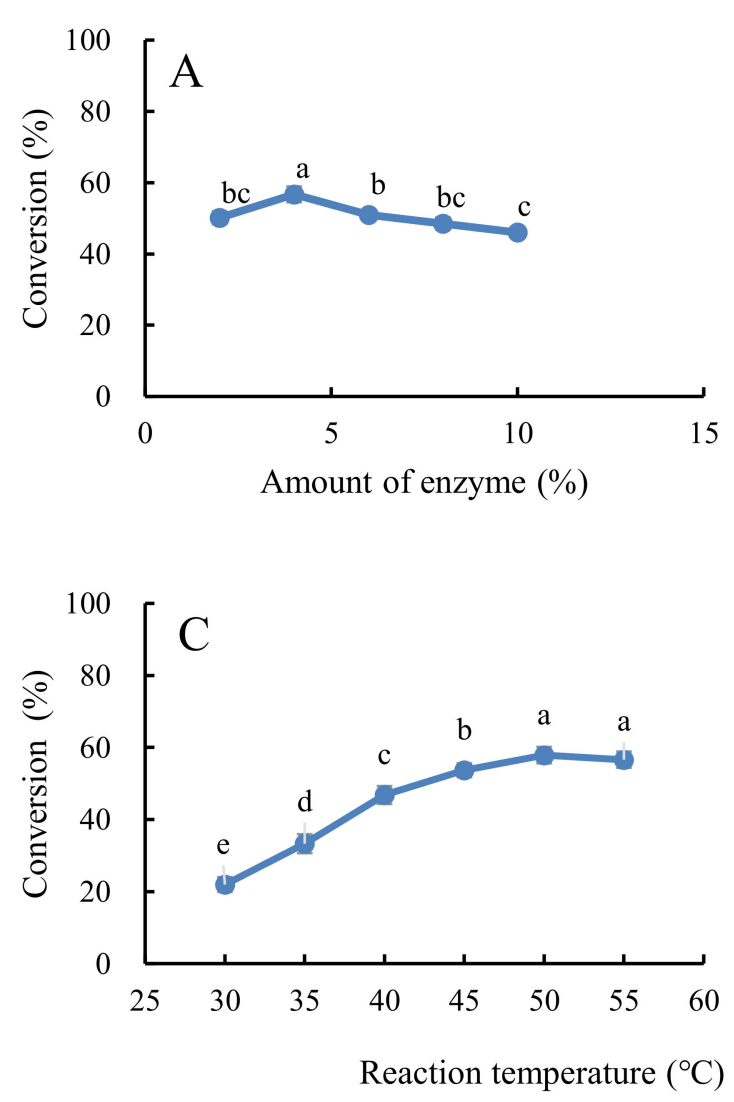
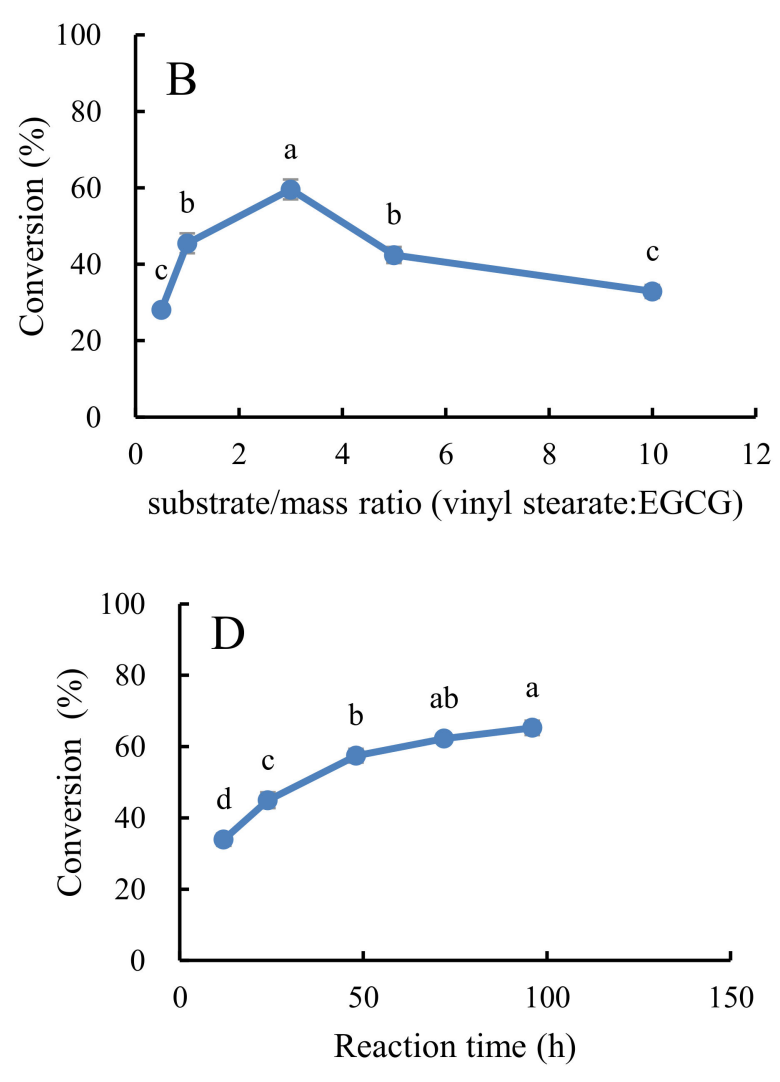

Figure 3. The effects of enzyme usage level with enzyme amount (lipase DF “Amano" $15, \% w / w$ of both substrates). (A), substrate mass ratio (B), reaction temperature (C), and reaction time (D) on the conversion of EGCG. Values followed by different letters within the same line are significantly different $(p<0.05)$.

The increased ratio of vinyl stearate to EGCG from 1:1 to 3:1 increased the conversion of EGCG from $28.1 \pm 1.1 \%$ to $59.6 \pm 2.5 \%$. The conversion then decreased to $32.9 \pm 1.7 \%$ at the ratio of 10:1 (Figure 3B). These results indicate that excess vinyl stearate may inhibit the catalytic ability of the lipase DF "Amano" 15 . Increased EGCG concentration reduced the substrate inhibition, thus enhancing ester synthesis.

The conversion showed a positive trend with reaction temperature at a certain reaction time (Figure 3C). The maximum conversion of EGCG occurred at $(57.9 \pm 2.3 \%)$ at $50{ }^{\circ} \mathrm{C}$. However, it slightly decreased at $55^{\circ} \mathrm{C}(56.6 \pm 2.2 \%)$, possibly due to the esterification of EGCG, which can change hydrolysis direction under high temperatures [13]. High temperatures enhance the interaction between enzymes and substrates [31]. High temperatures can also lead to a loss of enzyme activity by destroying its active conformation. Therefore, a suitable temperature is crucial for the enzyme-catalyzed reaction.

Although the reaction time was positively related to the conversion of EGCG (Figure 3D), the increasing trend significantly decreased after $48 \mathrm{~h}$. A slight increase in the conversion was observed from 48 to $96 \mathrm{~h}$ (from $57.4 \pm 1.9 \%$ to $65.2 \pm 2.0 \%$ ). Herein, a vinyl stearate and EGCG ratio of 3:1 achieved a conversion of $65.2 \%$ after a $4.0 \%$ addition of lipase DF "Amano" 15 in acetonitrile system at $50{ }^{\circ} \mathrm{C}$ for $96 \mathrm{~h}$.

\subsection{Identification and Structure Analysis of EGCG Stearyl Derivatives}

A semi-preparative high-performance liquid chromatography system was used to obtain the solution of the EGCG stearyl derivatives. The purified EGCG stearate derivatives (purity: $78.5 \%$ ) were obtained at $22.458 \mathrm{~min}$ and are shown in Figure S1. The MS spectra of EGCG derivatives are shown in Figure 4. The parent EGCG had a molecular weight of $457 \mathrm{Da}$, and that of the EGCG stearyl derivatives increased by $266 \mathrm{Da}$ for each 
additional vinyl stearate group. The mono-stearyl and di-stearyl EGCG peaked at $723 \mathrm{Da}$ and $990 \mathrm{Da}$, respectively.

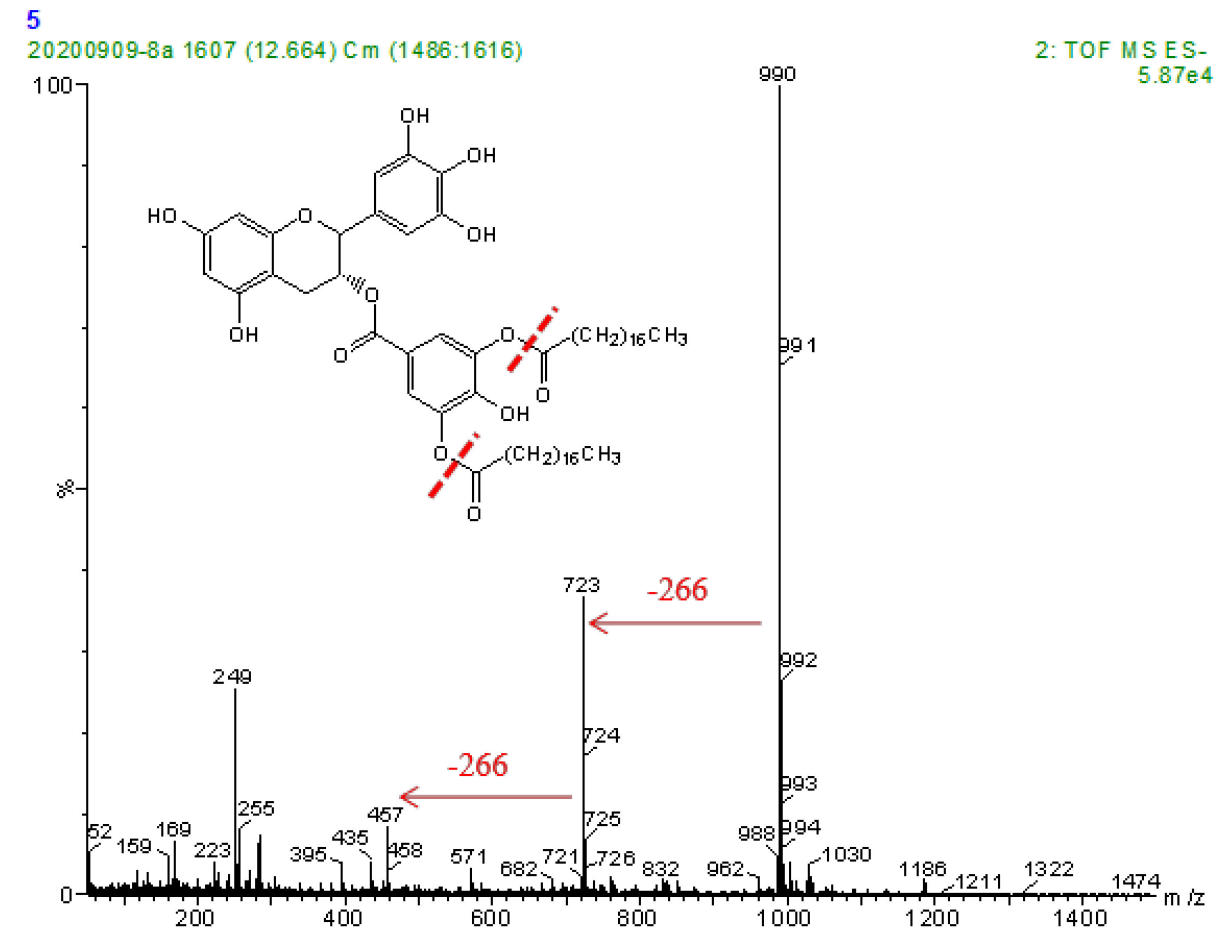

Figure 4. Mass spectra of EGCG stearyl derivatives.

The results of the NMR analysis for parent EGCG and di-stearyl EGCG are shown in Table 1. (1) Parent EGCG were as follows: $1 \mathrm{H}$ NMR (400 MHz, Methanol- $\left.d_{4}\right) \delta 6.97(\mathrm{~s}, 2 \mathrm{H})$, $6.52(\mathrm{~s}, 2 \mathrm{H}), 5.98(\mathrm{~s}, 2 \mathrm{H}), 5.55(\mathrm{ddd}, J=4.5,2.7,1.4 \mathrm{~Hz}, 1 \mathrm{H}), 4.99(\mathrm{~s}, 1 \mathrm{H}), 3.00$ (dd, $J=17.3$, $4.6 \mathrm{~Hz}, 1 \mathrm{H}), 2.86(\mathrm{dd}, J=17.4,2.7 \mathrm{~Hz}, 1 \mathrm{H}) .1 \mathrm{H}$ NMR $\left(400 \mathrm{MHz}\right.$, Methanol- $\left.d_{4}\right) \delta 6.97\left(\mathrm{H}-2^{\prime \prime}\right.$, $\left.6^{\prime \prime}\right), 6.52\left(\mathrm{H}-2^{\prime}, 6^{\prime}\right), 5.98(\mathrm{H}-6,8), 5.55(\mathrm{H}-3), 4.99(\mathrm{H}-2), 3.00(\mathrm{dd}, J=17.3,4.6 \mathrm{~Hz}, 1 \mathrm{H}), 2.86$ (H-4). 13C NMR (101 MHz, Methanol-d $\left.d_{4}\right) \delta 166.26$ (COO), 156.47 (C-7, 9), 155.83 (C-5), $145.29\left(\mathrm{C}-3^{\prime \prime}, 5^{\prime \prime}\right), 144.89\left(\mathrm{C}-3^{\prime}, 5^{\prime}\right), 138.39\left(\mathrm{C}-4^{\prime \prime}\right), 132.40\left(\mathrm{C}-4^{\prime}\right), 129.42\left(\mathrm{C}-1^{\prime \prime}\right), 120.14\left(\mathrm{C}-1^{\prime}\right)$, $108.88\left(\mathrm{C}-2^{\prime \prime}, 6^{\prime \prime}\right), 105.50\left(\mathrm{C}-2^{\prime}, 6^{\prime}\right), 98.04$ (C-10), 95.15 (C-8), 94.49 (C-6), 77.22 (C-2), 68.54 (C-3), $25.43(\mathrm{C}-4)$.

Table 1. ${ }^{1} \mathrm{H}$ and ${ }^{13} \mathrm{C}$ Chemical Shifts ( $\delta$ ) of EGCG and Di-stearyl EGCG.

\begin{tabular}{ccccc}
\hline & \multicolumn{2}{c}{ EGCG } & \multicolumn{2}{c}{ Di-Stearyl EGCG } \\
\hline C/H Position & ${ }^{\mathbf{1}} \mathbf{H}$ & ${ }^{13} \mathbf{C}$ & ${ }^{\mathbf{1}} \mathbf{H}$ & ${ }^{\mathbf{3}} \mathbf{C}$ \\
\hline 2 & 4.99 & 77.22 & 4.99 & 76.88 \\
3 & 5.55 & 68.54 & 5.57 & 68.38 \\
4 & 3.00 & 25.43 & 3.01 & 25.36 \\
& 2.86 & & 2.88 & \\
5 & & 155.83 & & 155.55 \\
6 & 5.98 & 94.49 & 5.98 & 94.30 \\
7 & & 156.47 & & 156.42 \\
8 & 5.98 & 95.15 & 5.98 & 95.01 \\
9 & & 156.47 & & 156.42 \\
10 & & 98.04 & & 97.98 \\
$1^{\prime}$ & & 120.14 & & 120.03 \\
$2^{\prime}$ & 6.52 & 105.50 & 6.51 & 105.51 \\
\hline
\end{tabular}


Table 1. Cont.

\begin{tabular}{ccccc}
\hline & \multicolumn{2}{c}{ EGCG } & \multicolumn{2}{c}{ Di-Stearyl EGCG } \\
\hline C/H Position & ${ }^{\mathbf{1}} \mathbf{H}$ & ${ }^{\mathbf{1 3}} \mathbf{C}$ & ${ }^{\mathbf{1}} \mathbf{H}$ & ${ }^{\mathbf{3}} \mathbf{C}$ \\
\hline $3^{\prime}$ & & 144.89 & & 145.11 \\
$4^{\prime}$ & 132.40 & & 132.41 \\
$5^{\prime}$ & & 144.89 & 6.51 & 145.11 \\
$6^{\prime}$ & & & 105.51 \\
$1^{\prime \prime}$ & 6.52 & 105.50 & 6.86 & 129.28 \\
$2^{\prime \prime}$ & & 129.42 & & 108.89 \\
$3^{\prime \prime}$ & 6.97 & 108.88 & & 149.75 \\
$4^{\prime \prime}$ & & 145.29 & 6.86 & 136.74 \\
$5^{\prime \prime}$ & & 138.39 & & 108.75 \\
$6^{\prime \prime}$ & 145.29 & & 166.21 \\
COO & 108.88 & & 170.68 \\
& 6.97 & 166.26 & & 172.44 \\
\hline
\end{tabular}

Proton and carbon in alkyl chain of incorporated fatty acids are not listed.

(2) Di-stearoyl EGCG were as follows: $1 \mathrm{H}$ NMR $\left(400 \mathrm{MHz}\right.$, Methanol- $\left.d_{4}\right) \delta 7.29(\mathrm{~m}$, $1 \mathrm{H}), 7.09(\mathrm{~h}, J=2.6 \mathrm{~Hz}, 0 \mathrm{H}), 6.97(\mathrm{~d}, J=4.7 \mathrm{~Hz}, 1 \mathrm{H}), 6.86(\mathrm{~d}, J=2.1 \mathrm{~Hz}, 0 \mathrm{H}), 6.68(\mathrm{~d}$, $J=2.1 \mathrm{~Hz}, 0 \mathrm{H}), 6.59(\mathrm{~d}, J=6.9 \mathrm{~Hz}, 1 \mathrm{H}), 6.51(\mathrm{~d}, J=4.5 \mathrm{~Hz}, 0 \mathrm{H}), 5.98(\mathrm{dd}, J=3.4,1.9 \mathrm{~Hz}$, $0 \mathrm{H}), 5.57(\mathrm{~m}, 1 \mathrm{H}), 4.99(\mathrm{~s}, 0 \mathrm{H}), 3.01(\mathrm{~m}, 1 \mathrm{H}), 2.88(\mathrm{dt}, J=17.5,2.7 \mathrm{~Hz}, 1 \mathrm{H}), 2.57(\mathrm{~m}, 2 \mathrm{H})$, $2.41(\mathrm{t}, J=7.4 \mathrm{~Hz}, 1 \mathrm{H}), 2.31(\mathrm{dt}, J=12.2,7.4 \mathrm{~Hz}, 0 \mathrm{H}), 2.17(\mathrm{~s}, 2 \mathrm{H}), 1.68(\mathrm{~m}, 2 \mathrm{H}), 1.45(\mathrm{q}$, $J=6.5,5.7 \mathrm{~Hz}, 1 \mathrm{H}), 1.31(\mathrm{~d}, J=3.7 \mathrm{~Hz}, 49 \mathrm{H}), 0.92(\mathrm{t}, J=6.7 \mathrm{~Hz}, 5 \mathrm{H}) .13 \mathrm{C} \mathrm{NMR}(101 \mathrm{MHz}$, Methanol- $\left.d_{4}\right) \delta 172.44(\mathrm{COO}), 170.86$ (COO), 166.21 (COO), 156.42 (C-7, 9), 155.55 (C-5), $149.75\left(\mathrm{C}-3^{\prime \prime}, 5^{\prime \prime}\right), 145.11\left(\mathrm{C}-3^{\prime}, 5^{\prime}\right), 136.74\left(\mathrm{C}-4^{\prime \prime}\right), 132.41\left(\mathrm{C}-4^{\prime}\right), 129.28\left(\mathrm{C}-1^{\prime \prime}\right), 120.03\left(\mathrm{C}-1^{\prime}\right)$, $108.89\left(\mathrm{C}-2^{\prime \prime}, 6^{\prime \prime}\right), 105.51\left(\mathrm{C}-2^{\prime}, 6^{\prime}\right), 97.98(\mathrm{C}-10), 95.01(\mathrm{C}-8), 94.30$ (C-6), 76.88 (C-2), 68.38 (C-3), 33.19 (-CH2), 31.70 (-CH2), 29.42 (-CH2), 29.39 (-CH2), 29.29 (-CH2), 29.10 (-CH2), 28.75 (-CH2), 25.36 (C-4), 24.57 (-CH2), 24.30 (-CH2), 22.83 (-CH2), 22.36 (-CH2), 13.08 $(-\mathrm{CH} 3)$.

The downfield shifts of the EGCG derivatives are shown in Table 1. The 1H NMR results showed that the D-ring of the EGCG molecule contained an acetyl group. The 13C NMR results showed the specific position of acylation. The remarkable upfield shift $(\Delta \delta$ 1.65) of $C-4$ ", and the significant downfield shift $(\Delta \delta 4.46)$ of $C-3^{\prime \prime}$ and $C-5^{\prime \prime}$ may be the acylation sites (Table 1). The carbons in the A-ring and C-ring did not have downfield or upfield shifts. Therefore, the structure of the di-stearyl EGCG was identified as $3^{\prime \prime}, 5^{\prime \prime}-2-\mathrm{O}-$ stearoyl epigallocatechin gallate (Figure 5).
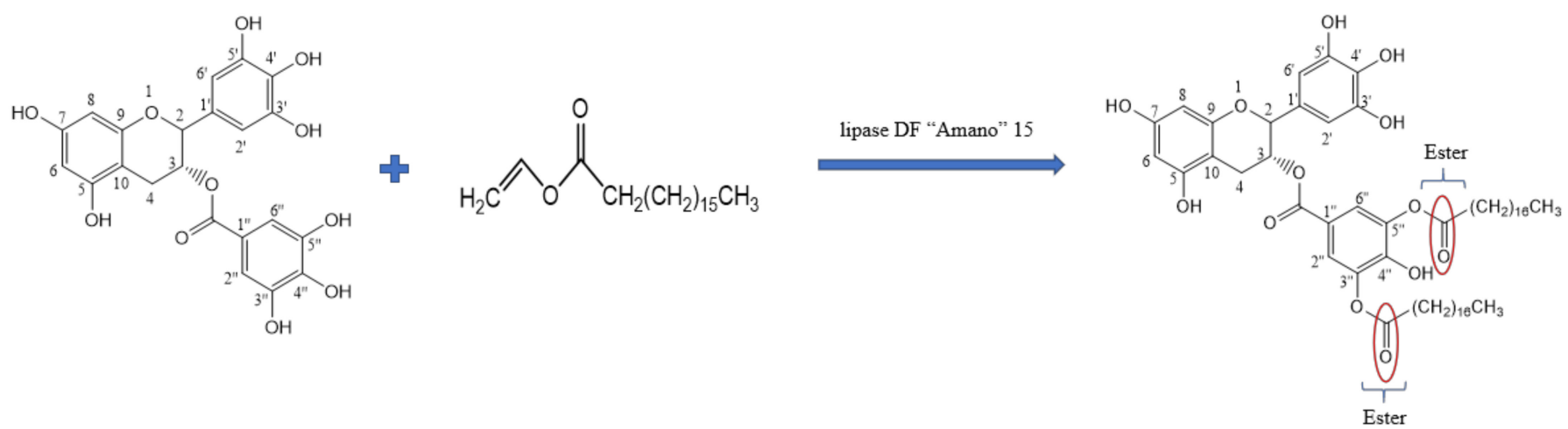

Figure 5. Schematic representation of enzymatic synthesis of di-stearyl EGCG. 


\subsection{Lipophilicity of EGCG Stearyl Derivatives}

Many hydrophilic bioactive compounds have been lipophilized for use in a lipophilic system [32-34]. The $\log P$ values of parent EGCG and EGCG stearyl derivatives are shown in Table $2(0.69 \pm 0.08$ and $3.49 \pm 0.34$, respectively) $(p<0.05)$. The $\log p$ value of EGCG stearyl derivatives was higher than that of the parent EGCG, as the stearyl group replaced the hydroxyl group. The enhanced lipophilicity of EGCG derivatives enhances the application of EGCG and other water-soluble antioxidants in the oxidation inhibition of fatty foods. These results further indicate that lipid acylation of EGCG significantly improves the lipid solubility of EGCG. The cell membrane permeability also increases due to increased fat solubility, thus increasing antioxidant activity [35].

Table 2. Lipophilicity of EGCG Stearyl Derivatives and Parent EGCG.

\begin{tabular}{cccc}
\hline & \multicolumn{4}{c}{ Octanol/Water Partition Coefficient (logP) } \\
\hline EGCG Stearyl & 3.49 & \pm & $0.34^{\mathrm{a}}$ \\
Derivatives & 0.69 & \pm & $0.08^{\mathrm{b}}$ \\
EGCG & & \pm
\end{tabular}

Values of three replicates (mean $\pm \mathrm{SD}$ ) with different letters were significantly different at $p<0.05$.

\subsection{Antioxidative Activities of EGCG Stearyl Derivatives and Synthetic Antioxidants}

Antioxidant assay methods can be divided into two categories based on chemical reaction mechanisms: electron transfer (ET) and hydrogen atom transfer (HAT) [36]. The antioxidative properties of EGCG, EGCG stearyl derivatives, BHT, BHA, and TBHQ are shown in Table 3. The DPPH has a deep violet color in the solution. Antioxidants can reduce the DPPH radicals to a yellow substance. The DPPH abilities of EGCG, EGCG stearyl derivatives, BHT, BHA, and TBHQ $(1 \mathrm{mg} / \mathrm{mL})$ were $90.89 \%, 51.49 \%, 9.74 \%, 72.38 \%$, and $92.99 \%$, respectively. ABTS can be converted to free radical cation by adding sodium persulfate and absorbed at $734 \mathrm{~nm}$. Herein, the ABTS abilities of EGCG, EGCG stearyl derivatives, BHT, BHA, and TBHQ were $90.36 \%, 65.16 \%, 56.30 \%, 60.06 \%$, and $63.01 \%$, respectively. The reducing power assay is a typical ET-based method, where antioxidants in acidic media reduce the iron $\left(\mathrm{Fe}^{3+}\right)$ ligand complex to a dark blue ferrous $\left(\mathrm{Fe}^{2+}\right)$ complex, and have a mix absorption at $700 \mathrm{~nm}$. The reducing power values of EGCG, EGCG stearyl derivatives, BHT, BHA, and TBHQ were $2.845,1.857,1.710,2.260$, and 2.689, respectively. Hydroxyl radicals can easily be generated via ultraviolet decomposition of $\mathrm{H}_{2} \mathrm{O}_{2}$ and have strong reactivity. Herein, the hydroxyl radical scavenging activities of EGCG, EGCG stearyl derivatives, BHT, BHA, and TBHQ were $30.71 \%, 16.84 \%, 11.33 \%, 7.18 \%$, and $73.86 \%$, respectively. The ORAC assay was used to determine the quenching effect of free radicals on fluorescent probes. Antioxidants can inhibit the fluorescence changes caused by free radicals. The results of AAPH-mediated FL oxidation of EGCG, EGCG derivatives, BHT, BHA, and TBHQ $(1 \mathrm{mg} / \mathrm{mL})$, are shown in Figure 6.

Table 3. Antioxidant Abilities of EGCG, EGCG Stearyl Derivatives, and Synthetic Antioxidants.

\begin{tabular}{|c|c|c|c|c|}
\hline & DPPH Inhibition(\%) & ABTS Inhibition (\%) & Reducing Power (OD) & Hydroxyl Inhibition (\%) \\
\hline EGCG & $90.89 \pm 2.56^{a}$ & $90.36 \pm 3.30^{a}$ & $2.845 \pm 0.086^{a}$ & $30.71 \pm 1.90^{b}$ \\
\hline EGCG Stearyl Derivatives & $51.49 \pm 1.80^{\mathrm{c}}$ & $65.16 \pm 1.28^{b}$ & $1.857 \pm 0.044^{c}$ & $16.84 \pm 1.18^{c}$ \\
\hline BHT & $9.74 \pm 0.65^{\mathrm{d}}$ & $56.30 \pm 2.30^{c}$ & $1.710 \pm 0.033^{c}$ & $11.33 \pm 0.80^{\mathrm{d}}$ \\
\hline BHA & $72.38 \pm 2.31^{b}$ & $60.06 \pm 2.88^{b c}$ & $2.260 \pm 0.063^{b}$ & $7.18 \pm 0.87^{\mathrm{e}}$ \\
\hline TBHQ & $92.99 \pm 2.06^{\mathrm{a}}$ & $63.01 \pm 1.64^{b}$ & $2.689 \pm 0.061^{a}$ & $73.86 \pm 2.87^{\mathrm{a}}$ \\
\hline
\end{tabular}

Values of three replicates (mean $\pm \mathrm{SD}$ ) with different letters were significantly different at $p<0.05$. 


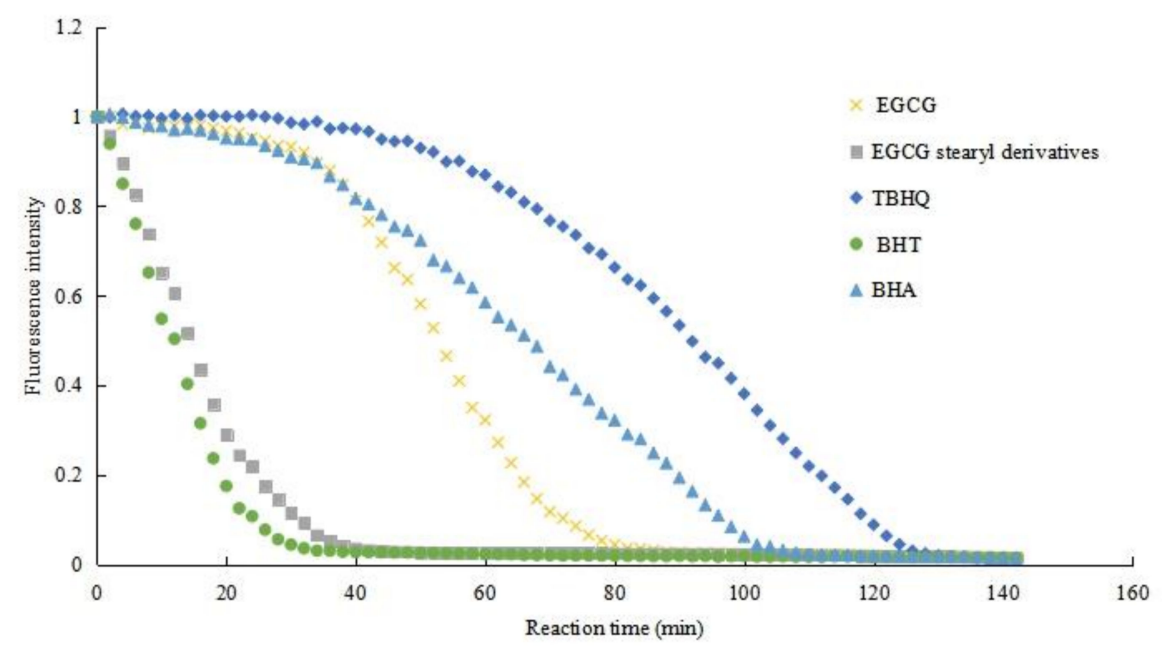

Figure 6. Oxygen radical absorbance capacity of EGCG, EGCG stearyl derivatives, and synthetic antioxidants.

Hydrophobicity is the main factor affecting the activity of phenolic compounds $[37,38]$. Although the antioxidant ability of EGCG stearyl derivatives was higher than or equal to that of BHA and BHT, it was lower than that of TBHQ. These results are similar to that of modified epicatechin, which has strong antioxidant and free radical scavenging abilities [39]. The coupling of alkyl groups to phenolic compounds reduced the free radical scavenging ability, indicating that the increase in chain length and the enhanced hydrophobicity do not necessarily improve the antioxidant capacity in emulsions [40]. Furthermore, Laguerre et al. [41] have shown that the increased hydrophobicity of antioxidants can drive the active site into the lipid phase, thus decreasing antioxidant ability.

POV is a widely used indicator of oil stability as a measure of hydrogen peroxide concentration during the oil oxidation stage. The POVs of soybean oil with the parent EGCG, stearyl EGCG, BHT, BHA, and TBHQ are shown in Figure 7. The POVs of soybean oil samples with EGCG, EGCG stearyl derivatives, BHT, BHA, and TBHQ were $48.50 \pm 1.23,18.17 \pm 0.92,36.61 \pm 0.95,30.84 \pm 0.92$, and $13.92 \pm 0.70 \mathrm{meq} / \mathrm{kg}$, respectively. The above POVs were significantly different from soybean oils $(55.29 \pm 1.59 \mathrm{meq} / \mathrm{kg})$ at the $21 \mathrm{~d}(p<0.05)$. Overall, oxidation reactions in bulk oil systems occur at the oil-air interface and/or the dissolved oxygen within the oil interface [42]. These results showed that the lipid oxidation inhibition ability was stronger in EGCG stearyl derivatives than in EGCG, but slightly less strong than in TBHQ. This finding suggests that EGCG stearyl derivatives may promote oil stability by activating the free radicals and phenolic hydroxyl reaction, whereas TBHQ uses phenyl ring [43]. The development of water-soluble natural polyphenols as EGCG stearyl derivatives could produce safe food additives with antioxidant properties, as an alternative to synthetic antioxidants which have been shown to have potential hazards. 


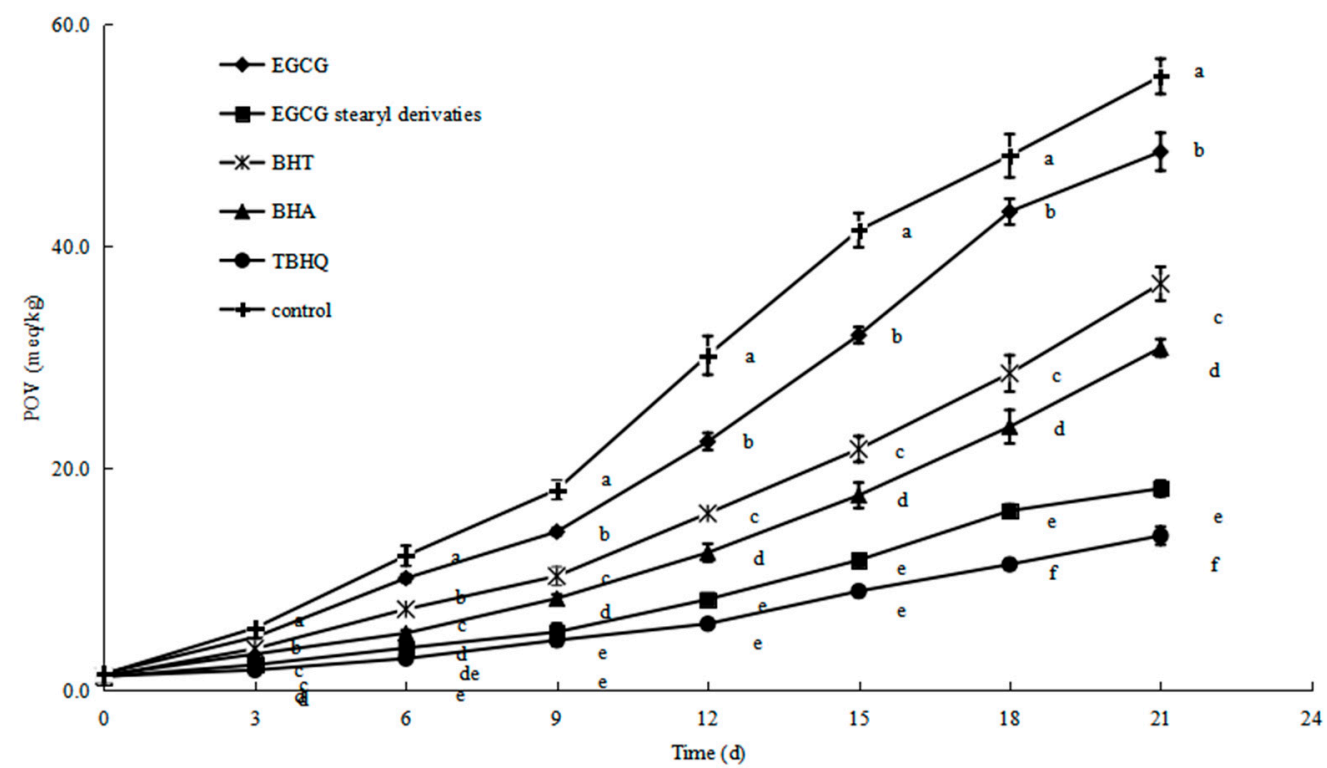

Figure 7. The POV of soybean oil containing EGCG, EGCG stearyl derivatives, and synthetic antioxidants under storage. Values followed by different letters within the same time are significantly different $(p<0.05)$.

\section{Conclusions}

We found that lipase DF "Amano" 15 had the highest activity and efficiency in the transesterification reaction between EGCG and vinyl stearate. A vinyl stearate: EGCG ratio of 3:1 achieved a $65.2 \%$ conversion of EGCG after $96 \mathrm{~h}$ at $50{ }^{\circ} \mathrm{C}$ in an acetonitrile system. HPLC-MS, and NMR identified the structure of the EGCG derivatives as 3",5"-2O-stearyl-EGCG. The EGCG stearyl derivatives have excellent lipophilicity. Moreover, their antioxidant ability and lipid oxidation inhibition abilities are higher than or equal to BHT, BHA, and parent EGCG. Compared with the chemical esterification of EGCG, which often produces toxic waste and unnecessary by-products, the enzymatic modification of EGCG is characterized by mild reaction conditions, environmental protection, and economic benefits. Finally, the excellent lipophilicity and antioxidative activity in the lipophilic system indicate that these derivatives have broad antioxidant application prospects in lipophile environments/high-fat food, and are suitable for use in the food, medicine and cosmetic industries.

Supplementary Materials: The following are available online at https:/ /www.mdpi.com/article/10 $.3390 /$ antiox10081282/s1. Figure S1. High performance liquid chromatography of the purification of EGCG stearyl derivatives.

Author Contributions: Conceptualization, S.Z.; Data curation, C.J.; Formal analysis, L.W.; Funding acquisition, H.W.; Investigation, C.J.; Methodology, L.W., X.H., S.Z., C.M. and H.W.; Project administration, H.W.; Resources, H.W.; Software, C.M.; Writing—original draft, C.J.; Writing—review and editing, L.W. and X.H. All authors have read and agreed to the published version of the manuscript.

Funding: This work was financially supported by the China National Key R\&D Program in the Period of 13th Five-year Plan (NO. 2017YFD0400803). This work was also supported by the National First-class Discipline Project of Food Science and Technology (NO. JUFSTR20180204).

Institutional Review Board Statement: Not applicable.

Informed Consent Statement: Not applicable.

Data Availability Statement: Data is contained within the article and Supplementary Materials.

Acknowledgments: The authors acknowledge to the Amano Enzyme Co., Ltd. for providing enzymes and for the scientific and technical advice provided during the study. Additionally, authors thank Tao Guanjun from the State Key Laboratory of Food Science and Technology of the Jiangnan 
University for support the Chromatography and Mass Spectrometry analysis. Finally, we are grateful to the Gu Xiaohong from the State Key Laboratory of Food Science and Technology of the Jiangnan University for the NMR analysis.

Conflicts of Interest: The authors declare that they have no conflict of interest.

\section{References}

1. Mozuraityte, R.; Kristinova, V.; Rustad, T. Oxidation of Food Components. In Encyclopedia of Food and Health; Elsevier: Amsterdam, The Netherlands, 2016; pp. 186-190.

2. Eskandani, M.; Hamishehkar, H.; Dolatabadi, J.E.N. Cytotoxicity and DNA damage properties of tert-butylhydroquinone (TBHQ) food additive. Food Chem. 2014, 153, 315-320. [CrossRef] [PubMed]

3. Echevarria, B.N.; Manzanos, M.J.; Goicoechea, E.; Guillén, M.D. 2,6-Di-Tert-Butyl-Hydroxytoluene and Its Metabolites in Foods. Compr. Rev. Food Sci. Food Saf. 2014, 14, 67-80. [CrossRef]

4. Vandghanooni, S.; Forouharmehr, A.; Eskandani, M.; Barzegari, A.; Kafil, V.; Kashanian, S.; Dolatabadi, J.E.N. Cytotoxicity and DNA Fragmentation Properties of Butylated Hydroxyanisole. DNA Cell Biol. 2013, 32, 98-103. [CrossRef] [PubMed]

5. Zhang, S.; Liu, X.; Mei, L.; Wang, H.; Fang, F. Epigallocatechin-3-gallate (EGCG) inhibits imiquimod-induced psoriasis-like inflammation of BALB/c mice. BMC Complement. Altern. Med. 2016, 16, 334. [CrossRef] [PubMed]

6. Lue, B.-M.; Nielsen, N.S.; Jacobsen, C.; Hellgren, L.; Guo, Z.; Xu, X. Antioxidant properties of modified rutin esters by DPPH, reducing power, iron chelation and human low density lipoprotein assays. Food Chem. 2010, 123, 221-230. [CrossRef]

7. Tadros, T.; Izquierdo, P.; Esquena, J.; Solans, C. Formation and stability of nano-emulsions. Adv. Colloid Interface Sci. 2004, 108-109, 303-318. [CrossRef] [PubMed]

8. Danihelova, M.; Viskupicova, J.; Šturdík, E. Lipophilization of flavonoids for their food, therapeutic and cosmetic applications. Acta Chim. Slovaca 2012, 5, 59-69. [CrossRef]

9. Figueroa-Espinoza, M.-C.; Villeneuve, P. Phenolic Acids Enzymatic Lipophilization. J. Agric. Food Chem. 2005, 53, 2779-2787. [CrossRef] [PubMed]

10. Tobiason, F.L. MNDO and AM1 Molecular Orbital and Molecular Mechanics Analyses of (+)-Catechin, (-)-Epicatechin, and their 3-O-Acetyl Derivatives. In Plant Polyphenols; Springer: Boston, MA, USA, 1992; pp. 459-478.

11. Ardhaoui, M.; Falcimaigne, A.; Ognier, S.; Engasser, J.; Moussou, P.; Pauly, G.; Ghoul, M. Effect of acyl donor chain length and substitutions pattern on the enzymatic acylation of flavonoids. J. Biotechnol. 2004, 110, 265-272. [CrossRef]

12. De Araújo, M.E.M.B.; Franco, Y.E.M.; Messias, M.C.F.; Longato, G.; Pamphile, J.A.; de Carvalho, P. Biocatalytic Synthesis of Flavonoid Esters by Lipases and Their Biological Benefits. Planta Medica 2016, 83, 7-22. [CrossRef]

13. Zhu, S.; Li, Y.; Li, Z.; Ma, C.; Lou, Z.; Yokoyama, W.; Wang, H. Lipase-catalyzed synthesis of acetylated EGCG and antioxidant properties of the acetylated derivatives. Food Res. Int. 2014, 56, 279-286. [CrossRef]

14. Viskupicova, J.; Danihelova, M.; Ondrejovic, M.; Liptaj, T.; Sturdik, E. Lipophilic rutin derivatives for antioxidant protection of oil-based foods. Food Chem. 2010, 123, 45-50. [CrossRef]

15. Matsumura, K.; Kaihatsu, K.; Mori, S.; Cho, H.H.; Kato, N.; Hyon, S.H. Enhanced antitumor activities of (-)-epigallocatechin-3O-gallate fatty acid monoester derivatives in vitro and in vivo. Biochem. Biophys. Res. Commun. 2008, 377, 1118-1122. [CrossRef]

16. Zhong, Y.; Shahidi, F. Lipophilized Epigallocatechin Gallate (EGCG) Derivatives as Novel Antioxidants. J. Agric. Food Chem. 2011, 59, 6526-6533. [CrossRef] [PubMed]

17. Minnelli, C.; Galeazzi, R.; Laudadio, E.; Amici, A.; Rusciano, D.; Armeni, T.; Cantarini, M.; Stipa, P.; Mobbili, G. Monoalkylated Epigallocatechin-3-gallate (C18-EGCG) as Novel Lipophilic EGCG Derivative: Characterization and Antioxidant Evaluation. Antioxidants 2020, 9, 208. [CrossRef]

18. Kontogianni, A.; Skouridou, V.; Sereti, V.; Stamatis, H.; Kolisis, F.N. Regioselective acylation of flavonoids catalyzed by lipase in low toxicity media. Eur. J. Lipid Sci. Technol. 2011, 103, 655-660. [CrossRef]

19. Chen, M.; Yu, S. Lipophilized Grape Seed Proanthocyanidin Derivatives as Novel Antioxidants. J. Agric. Food Chem. 2017, 65, 1598-1605. [CrossRef]

20. Gordon, M.H.; Paiva-Martins, F.; Almeida, M. Antioxidant Activity of Hydroxytyrosol Acetate Compared with That of Other Olive Oil Polyphenols. J. Agric. Food Chem. 2001, 49, 2480-2485. [CrossRef] [PubMed]

21. Asikin, Y.; Taira, I.; Inafuku, S.; Sumi, H.; Sawamura, M.; Takara, K.; Wada, K. Volatile Aroma Components and Antioxidant Activities of the Flavedo Peel Extract of Unripe Shiikuwasha (Citrus depressa Hayata). J. Food Sci. 2012, 77, C469-C475. [CrossRef] [PubMed]

22. Gülçin, I.; Mshvildadze, V.; Gepdiremen, A.; Elias, R. Screening of antiradical and antioxidant activity of monodesmosides and crude extract from Leontice smirnowii tuber. Phytomedicine 2006, 13, 343-351. [CrossRef]

23. Kong, S.; Cao, P.; Guo, J.; Su, Z. Antioxidant ofsmallmolecular weightchitosan oligosaccharidein vitro. BIO Web Conf. 2017, 8, 1028. [CrossRef]

24. Re, R.; Pellegrini, N.; Proteggente, A.; Pannala, A.; Yang, M.; Rice-Evans, C. Antioxidant activity applying an improved ABTS radical cation decolorization assay. Free Radic. Biol. Med. 1999, 26, 1231-1237. [CrossRef]

25. Du, L.-H.; Luo, X.-P. Lipase-catalyzed regioselective acylation of sugar in microreactors. RSC Adv. 2012, 2, 2663-2665. [CrossRef]

26. Yadav, G.D.; Devendran, S. Lipase catalyzed synthesis of cinnamyl acetate via transesterification in non-aqueous medium. Process. Biochem. 2012, 47, 496-502. [CrossRef] 
27. Lajis, A.F.B.; Hamid, M.; Ahmad, S.; Ariff, A.B. Comparative study of stirred and fluidized tank reactor for hydroxyl-kojic acid derivatives synthesis and their biological activities. Turk. J. Biochem. 2017, 43, 205-219. [CrossRef]

28. Arcos, J.A.; Hill, C.G., Jr.; Otero, C. Kinetics of the lipase-catalyzed synthesis of glucose esters in acetone. Biotechnol. Bioeng. 2001, 73, 104-110. [CrossRef]

29. Hazarika, S.; Goswami, P.; Dutta, N.N. Lipase catalysed transesterification of 2-o-benzylglycerol with vinyl acetate: Solvent effect. Chem. Eng. J. 2003, 94, 1-10. [CrossRef]

30. Yang, T.; Rebsdorf, M.; Engelrud, U.; Xu, X. Enzymatic Production of Monoacylglycerols Containing Polyunsaturated Fatty Acids through an Efficient Glycerolysis System. J. Agric. Food Chem. 2005, 53, 1475-1481. [CrossRef] [PubMed]

31. Xiong, J.; Huang, Y.; Zhang, H.; Hou, L. Lipase-Catalyzed Transesterification Synthesis of Geranyl Acetate in Organic Solvents and Its Kinetics. Food Sci. Technol. Res. 2014, 20, 207-216. [CrossRef]

32. Jakovetić, S.M.; Jugovic, B.; Gvozdenović, M.M.; Bezbradica, D.I.; Antov, M.G.; Mijin, D..; Knežević-Jugović, Z.D. Synthesis of Aliphatic Esters of Cinnamic Acid as Potential Lipophilic Antioxidants Catalyzed by Lipase B from Candida antarctica. Appl. Biochem. Biotechnol. 2013, 170, 1560-1573. [CrossRef] [PubMed]

33. Xie, D.; Yang, F.; Xie, J.; Zhang, M.; Liu, W.; Fu, L. A Rapid and Practical Catalytic Esterification for the Preparation of Caffeic Acid Esters. J. Chem. Res. 2014, 38, 695-700. [CrossRef]

34. Zengin, G. Synthesis, antimicrobial activity, and structure-activity relationships of eugenol, menthol, and genistein esters. Chem. Nat. Compd. 2011, 47, 550-555. [CrossRef]

35. Wang, M.; Zhang, X.; Zhong, Y.J.; Perera, N.; Shahidi, F. Antiglycation activity of lipophilized epigallocatechin gallate (EGCG) derivatives. Food Chem. 2016, 190, 1022-1026. [CrossRef]

36. Huang, D.; Ou, A.B.; Prior, R.L. The Chemistry behind Antioxidant Capacity Assays. J. Agric. Food Chem. 2005, 53, 1841-1856. [CrossRef] [PubMed]

37. Aliaga, C.; Rezende, M.C.; Arenas, A. How meaningful is the assessment of antioxidant activities in microheterogeneous media? Food Chem. 2009, 113, 1083-1087. [CrossRef]

38. Iglesias, J.; Pazos, M.; Lois, S.; Medina, I. Contribution of Galloylation and Polymerization to the Antioxidant Activity of Polyphenols in Fish Lipid Systems. J. Agric. Food Chem. 2010, 58, 7423-7431. [CrossRef]

39. Gao, Z.; Pan, Y.L.; Qin, A.X.; Kang, X.H.; Li, X.Y.; Jia, Y.N.; Chen, C.; Cui, T. Synthesis of Oil-Soluble Aliphatic Acylated Epicatechin and their Free Radical Scavenging Activity. Adv. Mater. Res. 2013, 781-784, 1424-1429. [CrossRef]

40. Yuji, H.; Weiss, J.; Villeneuve, P.; Giraldo, L.J.L.; Figueroa-Espinoza, M.-C.; Decker, E.A. Ability of Surface-Active Antioxidants to Inhibit Lipid Oxidation in Oil-in-Water Emulsion. J. Agric. Food Chem. 2007, 55, 11052-11056. [CrossRef] [PubMed]

41. Laguerre, M.; Chen, B.; LeComte, J.; Villeneuve, P.; McClements, D.; Decker, E.A. Antioxidant Properties of Chlorogenic Acid and Its Alkyl Esters in Stripped Corn Oil in Combination with Phospholipids and/or Water. J. Agric. Food Chem. 2011, 59, 10361-10366. [CrossRef]

42. Budilarto, E.S.; Kamal-Eldin, A. The supramolecular chemistry of lipid oxidation and antioxidation in bulk oils. Eur. J. Lipid Sci. Technol. 2015, 117, 1095-1137. [CrossRef] [PubMed]

43. Ai-Li, J.; Chang-Hai, W. Antioxidant properties of natural components from Salvia plebeia on oxidative stability of ascidian oil. Process. Biochem. 2006, 41, 1111-1116. [CrossRef] 